\title{
Hydraulic optimization and modeling of hydro- cyclone-systems for treatment and purification of any kind of waters
}

\author{
Lars Spangemacher ${ }^{1, *}$, Siegmund Fröhlich $^{1}$, and Hauke Buse \\ ${ }^{1}$ Hochschule Emden/Leer, Constantiplatz 4, 26723 Emden
}

\begin{abstract}
Water is an indispensable resource for many purposes and good drinking water quality is essential for mankind. This article is supposed to show the need for mobile water treatment systems and therefore to give an overview of different mobile drinking water systems and the technologies available for obtaining good water quality. The aim is to develop a simple to operate water treatment system with few processing stages such as multi-cyclone-cartridge and reverse osmosis with energy recuperation, while the focus is set on modeling and optimizing of hydrocyclone systems as the first treatment stage.
\end{abstract}

\section{Introduction}

Good water quality is essential for mankind and an indispensable resource for many purposes. Corresponding to the growing number of people on earth, the worldwide water demand also rises continuously. Today, already $20 \%$ of the world's population experiences a substantial lack of accessible drinking water resources - yet the demand is expected to keep rising dramatically over the next years [1].

Statistic figures confirm the urgency for change. Millions of people have died due to insufficient water quantity and drinking contaminated water. According to the WHO, approximately $88 \%$ of worldwide diseases result from polluted water [2] And, following UNO, there are roughly 263 "international water resources" - corresponding to approx. 60 $\%$ of global water occurrence - where legal claims to water usage remain unsettled [3]. That leads to serious conflicts and triggers the migration of thousands towards clean water resources.

In the tragic event of natural disasters, political conflicts or extreme climate situations the existing water shortage becomes particularly urgent. As such, tsunamis, hurricanes or earthquakes like, for example, in Nepal in April 2015 have shown that rural places are especially vulnerable to malfunctioning water supply. Although Kathmandu's water supply was re-established within a few days, people living in isolated mountain regions had to wait weeks or even months to receive good drinking water after the reconstruction of water supply systems.

\footnotetext{
*Corresponding author: lars.spangemacher@hs-emden-leer.de
} 
The aim of this research is to develop a safe and reliable technology, which is capable of supplying drinking water in any of the above mentioned tragic events.

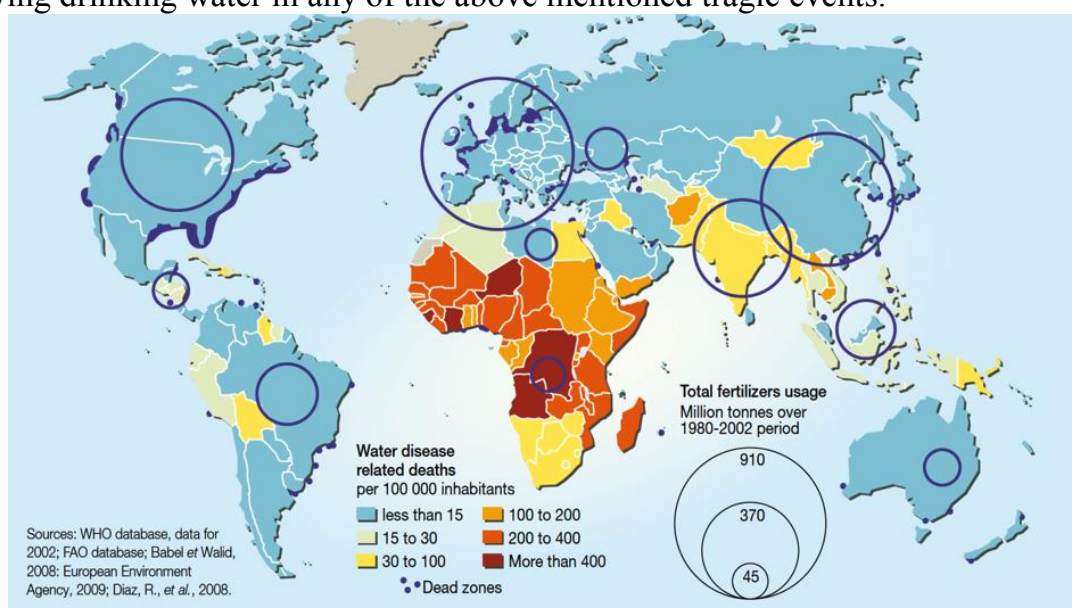

Fig. 1. Water diseases related death [2]

The rising water shortage in many world regions has different causes. They include the rising world population, which boosts the high agricultural water consumption and the increase of water pollution. However, the problem of water shortage affects different populations more or less severely. Due to unbalanced water distribution, unpolluted drinking water is taken for granted by some, whereas other populations regard it as precious commodity. Common strategies to solve that supply problem range from sustainable water usage, multi usage of water up to long distance transport of water. According to many population development prognoses the drinking water demand will rise drastically, because the world population will grow intensively in the next decades.

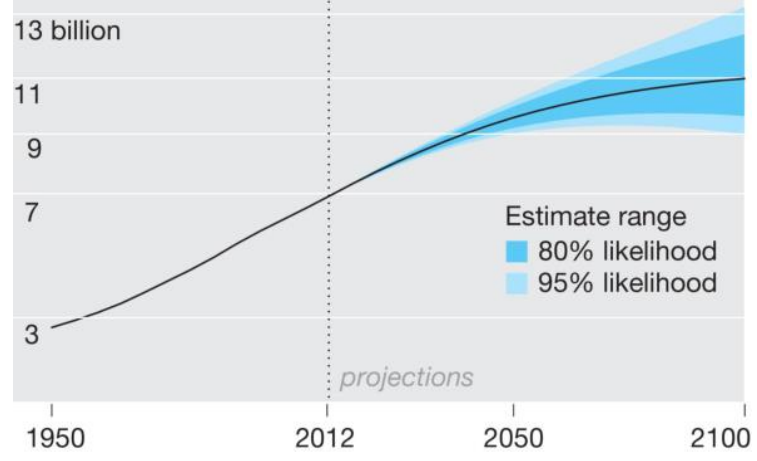

Fig. 2. World population prognosis 2100 [4]

In fact, countries such as Kenya, Egypt, Tunisia, Israel, Saudi Arabia, Jordan Kuwait, Ruanda or Bahamas are especially vulnerable to water scarcity. In the forthcoming years huge countries like China, India, Mexico, Nigeria and others will also be threatened by increasing water stress.

As consequences of those scenarios for the governments of those countries and for the international foreign aid organizations there is huge advantages coming soon 


\subsection{Catastrophes and other causes of water stress and water shortage}

Particular importance results in terms of natural catastrophes, military conflicts and extreme climatic situations. In the past, natural catastrophes caused by earthquakes, tsunamis, hurricanes and others have led again and again to insufficient supply of drinking water. In case of disastrous earthquakes as, for example, in Nepal 2015 the drinking water supply of rural mountain regions was not restored for weeks or months. Acc. UNICEF approximations only $20 \%$ of inhabitants had access to safe water sources.

Those catastrophic incidences of insufficient water access are likely to be followed by malnutrition and devitalization among first and foremost children. These conditions can be live-threatening. In 2015, nearly 1,7 million Nepali children were affected. Although in the urban region of Kathmandu the drinking water distribution could be restored within few days [5] far regions in the surrounding mountains were disconnected for weeks or longer from good drinking sources. The restoration of plenty kilometers of the water grid took such a long time.

\subsection{Mobile Drinking Water Unit Demand for Difficult Accessible Rural Regions}

Nowadays there are several transportable drinking water plants available on the market. The biggest disadvantage of them is their few cubic meters production output per hour. For example, the German Public Social Aid Organization (Technisches Hilfswerk - THW) disposes plants based on a modular system, which contains up to seven process steps at a water production rate of few cubic meters per hour. Beside a rather big space requirement and adequate logistics, the effort of qualified personnel and necessary chemicals and auxiliary materials also quite high. Such a support of far rural regions as in Nepal is realizable only at high expenses.

\subsection{State of Art of Mobile Drinking Water Processing}

Current mobile plant technologies available on the market for such disaster management are based on several process engineering unit operations $[6,7]$ as:

- mechanical separation of solids and waste by sieves, filters, etc. [6]

- $\quad$ physical processes as sedimentation, flotation, aeration or adsorption [7]

- $\quad$ aerobic or anaerobic biological water purification [8]

- membrane processes as reverse osmosis or electro dialysis [9]

- vacuum processes as mechanical vapor compression [10]

- thermic processes as distillation or multi-stage-flash-processes [11] or

- water chlorination [12] and

- UV-disinfection [13]

However, the biggest weakness of these state of art systems is their poor water production rate. Additionally, those multistage systems are massive in size and need specially trained personnel to oversee the difficult procedure and ensure good results. That implies, that the produced drinking water with such state of art plants is for the most people in crisis situations as well not technologically as well economically realizable.

An essential process to create a compact, smart and mobile drinking water production unit is reverse osmosis. Reverse osmosis is a unique technology, which can eliminate as well as dissolve inorganic and organic compounds. After a pre-treatment of solid- and oilelimination this process is able to assure adequate drinking water quality and quantity. 
Since more than 40 years diverse processes of water desalination are established to stop the water shortages worldwide. But all of them come with quite high cost investments and huge energy demands to produce drinking water. Therefore, water desalination plants were initially installed mostly in quite rich counties. Most of those seawater desalination plants are located in Middle East, North America and Mediterranean Countries. At this moment there are more than 14.000 stationary large scale seawater desalination plants operating worldwide, which produce a total of over $95 \mathrm{mln}$. cubic meter per day.

Technological progress took place in those plants, so the lowering of invest costs and energy demand made sure, that the reverse osmosis process is the most successful technique to deliver best quality drinking water. Particularly the implementation of energy recovery modules in the high pressure hydraulic part could lower substantially the energy demand of desalination.

\section{A New technological Solution}

At the University of Applied Sciences Emden-Leer, we are designing a system for mobile water treatment which draws on approved concepts, yet improving them in several aspects. Drinking water treatment plants must purify raw water, originating from wells or surface waters, in several process steps. There are already various methods implemented, such as filtration (table 1), followed by chemical (chlorination / iodination) or physical (irradiation by ultraviolet light) disinfection process steps.

Table 1. Filtration methods (Drews, A.; TU Berlin - Principles of membrane processes)

\begin{tabular}{|r|l|r|l|}
\hline Pore size & \multicolumn{1}{|c|}{ Process } & \multicolumn{1}{|c|}{$\begin{array}{c}\text { Filtration } \\
\text { pressure }\end{array}$} & \multicolumn{1}{|c|}{ Separation of } \\
\hline$>10 \mu \mathrm{m}$ & Filter & & \\
\hline$>0,1 \mu \mathrm{m}$ & Microfiltration & $<2 \mathrm{bar}$ & Bacteria, yeast, particles \\
\hline $100-2 \mathrm{~nm}$ & Ultrafiltration & $1-10 \mathrm{bar}$ & Macro molecules, protein \\
\hline $2-1 \mathrm{~nm}$ & Nano filtration & $3-20 \mathrm{bar}$ & Viruses, 2-valent Ions \\
\hline$<1 \mathrm{~nm}$ & Reverse Osmosis & $10-80 \mathrm{bar}$ & Salt, small organic molecules \\
\hline
\end{tabular}

As all established purification processes $[6,14]$ have a significantly high energy demand, especially in disaster areas without functioning energy infrastructure, usage does not come without problems. The proposed plant concept for mobile drinking water treatment consists of a 2-step treatment process.

Step 1: Reject Separation by means of a new hydrocylone cartridge

Step 2: Reverse Osmosis (RO) with energy recuperation

As one design parameter for the drinking water treatment plant, this process aimed at producing of $20,000 \mathrm{l} / \mathrm{h}$, which is sufficient to supply up to 25,000 people [15]. The system concept is scalable to almost any size due to its modular design - allowing higher production rates of drinking water.

\subsection{Step 1 - Hydrocyclone cartridge}

A newly developed hydrocyclone cartridge forms the first stage of the water treatment concept. This cartridge will combine many individual hydrocyclones with common hydraulic connections requiring very small space. The separation limit d50 is designed to 5 microns; for efficient separation of both waterborne inert particles and (micro-) organisms. 
Hydrocyclones have long tradition in the field of particle separation, especially in mining and basic materials industry, while they are characterized by a maintenance free operation.

Within the scope of a research project different types of hydrocyclones have been tested regarding their separation performance as a first stage for mobile drinking water treatment. From these results a very compact Version was designed. It combines several single hydrocyclones in a small chamber with common hydraulic connections while aiming at a separation limit of $\mathrm{d} 50: 5 \mu \mathrm{m}$; sufficient to separate inert particles as well as microorganisms from water. Due to patenting this hydrocyclone cartridge cannot be revealed at this time.

\subsection{Step 2 - Reverse osmosis}

A second stage reverse osmosis (RO) filtration ensures a germ-free drinking water due to the small membranes pore size. Common RO-systems have the disadvantage of consuming high amounts of energy in order to reach the high pressure needed at the primary membrane side. Newly developed large scale seawater desalination plants solve this dilemma by means of mechanical energy-recovery.

By using energy recovery processes the disadvantage of high energy consumption will be compensated to a large extend. Thus, this technology can also operate on temporary power generators (e.g. mobile photovoltaic generators). A modern high pressure pump requires due to its energy recovery approx. 40\% less electrical energy [16] compared to traditional pumps without any energy recovery option. This is done by recirculating unused feed water to the pump unit.

The main advantage of using a reverse osmosis - after solid separation by means of hydrocylones - is the possibility to process any sweet water as well as seawater loaded with any kind of organic and inorganic matter to reach a water quality according drinking water ordinance. Depending on the pore size of the RO membrane, microelements can be removed almost completely to ensure good drinking water quality without any hazards regarding human health.

\section{Modeling of a hydrocyclone prototype}

There are numerous approaches for modeling of hydrocyclones which can be broken down to 7 different categories. Their validity is mostly restricted as most of them were developed by use of empirical data. The following description is limited to the so called thin stream classification with volume concentrations $c_{v}<\sim 10 \%$ [17]

The contemplation by Trawinski provides the following statement with regard to separation size. Particles will be separated in case their sedimentation velocity $w_{f z}$

$$
w_{f z}=\frac{\Delta \rho}{18 \eta} d_{S t, t}^{2} \cdot r_{i} \cdot w^{2}
$$

in the centrifugal field is larger than the median introversive radial velocity $v_{r i}$.

$$
v_{r i}=\frac{v_{o}}{2 \cdot \pi \cdot r_{i} \cdot h_{i}}
$$

In terms of separation size $x_{t}$, here as stoke diameter $d_{S t, t}$, the equality of velocities applies:

$$
w_{f z}=v_{r i}
$$

Formally this correlates to the equality between surface loading and settling velocity.

Therefore we get 


$$
d_{S t, t}^{2}=\frac{18 \eta}{\Delta \rho} \cdot \frac{V o}{2 \pi r_{i}^{2} \varpi^{2} h_{i}}
$$

The upstream volume flow $V_{O}$ is proportional to the total volume flow $V_{A}$ where Trawinski makes the following assumption:

$$
V_{A} \sim d_{e} \cdot d_{o} \cdot \sqrt{\Delta \rho / \rho} \sim V_{o}
$$

The idea behind this assumption is that hydrocyclones, with regard to pressure drop, can be seen as a pipe with a median diameter $\sqrt{d_{e} \cdot d_{o}}$. Assuming the proportionality $\mathrm{d}_{\mathrm{e}} \cdot \mathrm{d}_{\mathrm{o}} \sim D^{2}$ and $\mathrm{h}_{\mathrm{i}} \sim \mathrm{L}$ we get:

$$
d_{S t, t} \sim \sqrt{\frac{18 \eta}{\Delta \rho}} \cdot \sqrt{\frac{D}{L}} \cdot \frac{\sqrt{D}}{\sqrt[4]{\Delta \rho / \rho}}
$$

Here we can see, that $d_{S t}{ }^{*}$ is getting smaller (and separation is becoming better) the smaller the hydrocyclone diameter and the slighter the cyclone is. The difference in pressure which is applied to the hydrocyclone only has a small impact The first factor, where changes in given material systems are not possible, is the characteristic material system combination in all sedimentation equations, if only the stokes condition of viscous particle flow is fulfilled. A similar correlation for the median separation size $d_{T}$, which considers the volume flow ration $\frac{V_{O}}{V_{U}}$ and the solid volume concentration $C_{v}$, has been developed by Neeße and Schubert with the help of their model of turbulent cross-flow classification:

$$
d_{T}=K \sqrt{\frac{\eta m}{\Delta \rho}} \cdot \frac{\sqrt{D}}{\sqrt[4]{\frac{\Delta \rho}{\rho m}}} \cdot \sqrt{\frac{\ln \frac{V_{O}}{V_{u}}}{\left(I-c_{v}\right)^{4,65}}}
$$

$\mathrm{K}$ is a specific adaptation constant with the value $\mathrm{K}=0,12$ for the version used by Neeße and Schubert. For the material values $\rho_{m}$ and $\eta_{m}$ density and viscosity of the suspension have to be used. The median suspension density is calculated depending on the volume concentration $\mathrm{C}_{\mathrm{V}}$ as follows:

$$
\rho_{m}=\rho_{s} \cdot \rho_{v} \cdot+\rho_{f} \cdot\left(1-c_{v}\right)
$$

whereas $\rho_{s}$ and $\rho_{f}$ shall be the solid density and liquid density. The median suspension viscosity for concentrations up to about $30 \%$ is calculated by:

$$
\eta_{m}=\eta \cdot\left[1+\frac{1,25 \cdot c_{v}}{1-c_{v} / c_{\max }}\right]^{2}
$$

The solid volume portion $C_{V \text { max }}$ for the sedimented suspension the value is in the range between 0,63 and 0,84 .

Apart from cut size also throughput and pressure drop are important parameters. They are linked together by the following formula:

$$
V=K_{V} \cdot d_{e} \cdot d_{o} \cdot \sqrt{\Delta \rho / \rho}
$$

with $\mathrm{Kv} \operatorname{Rj} 0,33 \ldots 0,39$ for long construction types ( $L / D>$ approx. 2$)$ and $\mathrm{Kv} \operatorname{Rj} 0,22 \ldots 0,28$ for short construction types

The distribution of upstream and downstream is defined by the diameters $d_{o}$ and $d_{u}$. There also exist empirically adapted formulas, e.g. from Tarjan

$$
\frac{V_{o}}{V_{U}} \approx 0,91 \cdot\left(d_{o} / d_{u}\right)^{3}
$$

Rietema established the following optimal proportions for dimensioning of hydrocyclones with regard to cut zise, throughput and pressure drop 
Table 2. Optimal hydrocyclone proportions according Rietema

\begin{tabular}{|c|c|c|c|c|c|}
\hline $\begin{array}{c}d_{o} / D \\
{[\text { in mm }]}\end{array}$ & $\begin{array}{c}d_{u} / D \\
{[\text { in mm }]}\end{array}$ & $\begin{array}{c}d_{e} / D \\
{[\text { in mm }]}\end{array}$ & $\begin{array}{c}L / D \\
{[\text { in mm }]}\end{array}$ & $\begin{array}{c}\left(L-h_{i}\right) / D \\
{[\text { in mm }]}\end{array}$ & $\begin{array}{c}\text { Cone angle } \\
{\left[\text { in }^{\circ}\right]}\end{array}$ \\
\hline 0.25 & 0.8 & 0.25 & 9.63 & 0.94 & $6^{\circ}$ \\
\hline
\end{tabular}

\section{Experimental results}

Tests with model media have been conducted. Therefore the new hydrocyclone prototype has been benchmark tested with a commercially available cyclone. Tests were run at different conditions while changing the parameters input pressure (and respectively input volume flow) as well as downstream nozzle diameter. These tests have shown, that the hydrocyclone prototype is capable in achieving similar or even better results with regard to solid concentration reduction.

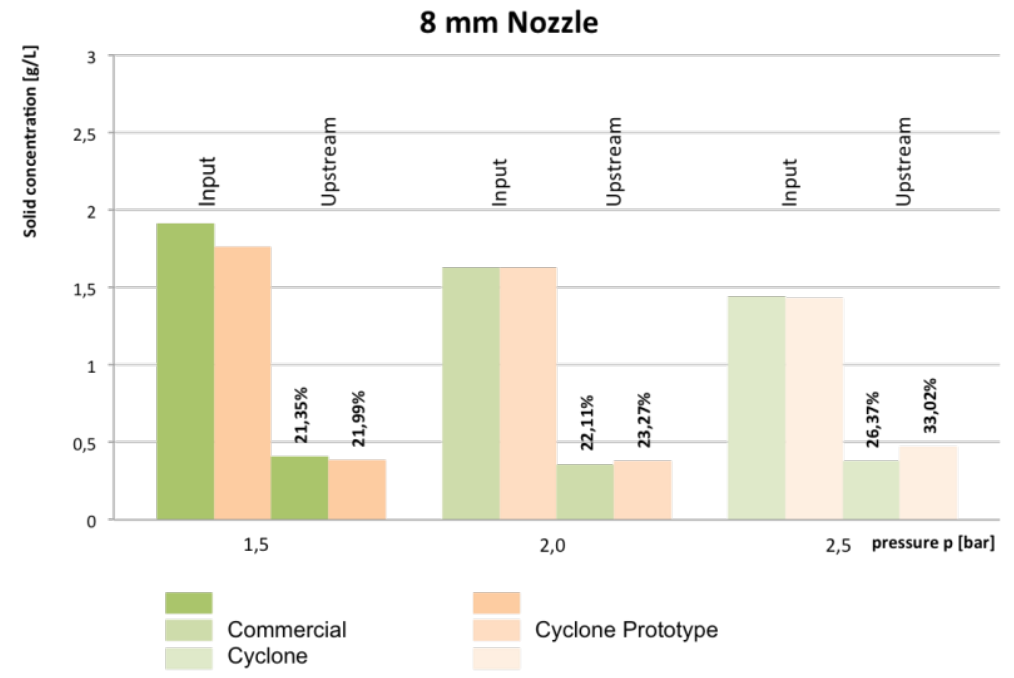

Fig. 3. Results comparing commercially available hydrocyclone with prototype development (here with $8 \mathrm{~mm}$ downstream nozzle)
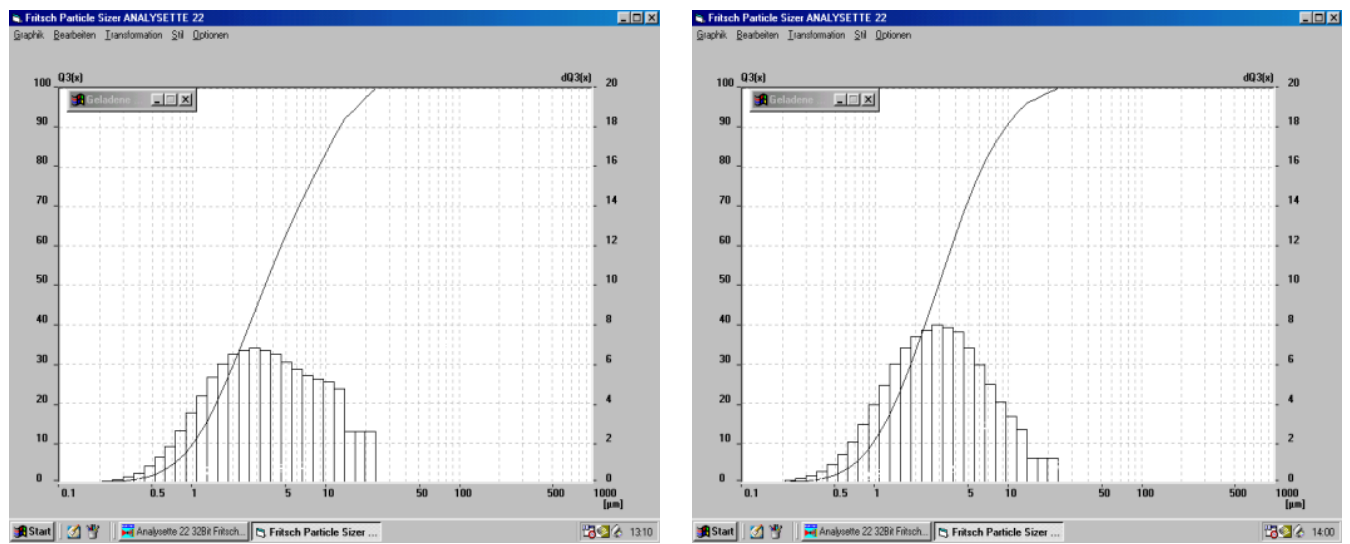

Fig. 4. Particle distribution (left: prototype; right: comm. hydrocyclone) 


\section{Conclusion}

In general we can conclude, that hydrocyclone systems are capable of removing solids and other large particles from water as a first treatment stage for mobile drinking water purification systems, whereas parameters such as downstream nozzle diameter as well as input pressure and respectively the volume flow have a strong impact on the degree of purity of the treated water. Further investigations have to be conducted using water from natural sources to analyze the purification potential

\section{Scientific Literature}

1. G. Rüschelmeyer "Das Parlament" des Deutschen Bundestags und Bundeszentrale für politsche Bildung (2006)

https://www.bundestag.de/dasparlament/2006/25/Thema/017.html

2. http://www.who.int/water_sanitation_health/diseases (2016)

3. M. Kalinin, UN Water Transb. waters: Sharing Benefits, Sharing Respons. http://www.unwater.org/downloads/UNW_TRANSBOUNDARY.pdf (2008)

4. R. Kunzig, Nat. Geogr. http://news.nationalgeographic.com/news/2014/09/140918population-global-united-nations-2100-boom-africa/ (2014)

5. THW, unknown author, https:/www.thw.de/SharedDocs/Meldungen/DE/Einsaetze/international/2015/05/meldu ng_003_nepal_trinkwasserversorgung_beendet.html?nn=922620 (2015)

6. K. Hancke, Wasseraufbereitung, Springer (2003), ISBN:978-3540068488

7. P. A. Schweitzer, Handbook of Separation Techniques for Chemical Engineers, 4-161ff, ISBN:0-07-057061 (1996)

8. A. C. van Haandel, J. G. M. v.d. Lubbe, Handbook of Biological Wastewater Treatment, 575ff, ISBN:9781780400006 (2012)

9. A. Basile, Handbook of Membrane Reactors, Woodhead Publishing, 478ff, ISBN:9780857094148 (2013)

10. F. Lokiec, A. Ophir, The Mechanical Vapor Compression: 38 Years of Experience, IDA World Congress Maspalomas, Gran Canaria - Spain Oct. 21.-26. (2007)

11. Abraha Woldai, Multi-Stage Flash Desalination, CRC Press - Engineering Systems and Sustainability, 27ff, ISBN:978-1-4987-21170 (2016)

12. D. J. Gates, Chlorine Dioxide Handbook - Water Disinfection Series, ISBN: 9780898679427 (1998)

13. J. R. Bolton, C. A. Cotton, The Ultraviolet Disinfection Handbook, American Water Works Association, ISBN:9781583215845 (2008)

14. W. Lorch, Handbook of Water Purification, ISBN978-0133728712 (1998)

15. P. Gleick, Basic water requirements for human activities: Meeting basic needs Pac. Inst. f. stud. in dev., env. and sec. in wat. int., 21, 83-92 (1996)

16. M. Elimelech, W. -A. Phillip, The Future of Seawater Desalination: Energy, Technology, and the Environment, Science, 333 (2011)

17. M. Stieß, Mechanische Verfahrenstechnik 2, Springer, 167ff (1997) 